\title{
HOLMES, Douglas. 2014. Economy of Words: Communicative Imperatives in Central Banks. Chicago: University of Chicago Press. 280 pp.
}

\section{Louise Scoz Pasteur de Faria}

Douglas Holmes é professor de antropologia na State University of New York em Binghamton. Seu nome é atrelado ao desenvolvimento de estudos sobre finanças e eco-nomia dentro do campo da Antropologia Econômica Contemporânea.

A tradição clássica dos estudos sociais da economia coloca em questão os modos através dos quais a Economia ${ }^{1}$, os mercados e os sujeitos econômicos são socialmente construídos. Essa tradição se coloca em contraposição ao argumento defendido por grande parte da ciência econômica na qual a Economia era pensada como um resultado natural que parte de disposições humanas não sociais. $\mathrm{O}$ argumento central é que a Economia não é um domínio alheio ao social, mas parte de uma trama complexa de relaçóes sociais que operam lógicas que não necessariamente podem ser compreendidas dentro do escopo da racionalidade econômica.

Estudos contemporâneos da Antropologia Econômica continuam, em grande parte, adotando essa postura crítica com relação à Teoria Econômica. Entretanto, a questão predominante não é tanto a natureza social da economia, mas sim como o Econômico é efetivamente construído. Essa é uma agenda de pesquisas e desenvolvimentos teóricos influenciados pelos estudos sociais das ciências que pensa o papel do governo, do mercado e da teoria econômica no fazer da própria economia a partir da descrição etnográfica. Isso significa que antropólogos dedicados a pensar a economia têm entrado cada vez mais em espaços de poder como instituições financeiras, bancos centrais, empresas e governos para entender como teorias, técnicas, práticas, tecnologias e agentes econômicos produzem a Economia.

Economy of Words é resultado de uma trajetória de pesquisa iniciada na década de 1980 e compóe uma trilogia de publicações iniciada por Cultural Disenchantments (1989) e Integral Europe (2000) a respeito dos aspectos comunicacionais da Economia. A temática que entrelaça essa composição de publicações emerge dessa inquietação: a necessidade de levar a sério o que "meras palavras" 2 podem efetivamente fazer na economia.

Douglas Holmes se dispõe a acompanhar como protocolos de inflation targeting, modelos pensados para gerir inflação, foram implementados pelas instituições financeiras que fizeram parte de seu trabalho de campo, iniciado em setembro de 2008 até agosto de 2010 nos bancos centrais Riksbank, na Suíça, Bundesbank, na Alemanha e European Central Bank, com sede em Frankfurt.

Como o autor mesmo define, esse é um livro sobre a criação de um regime monetário, sobre a natureza da produção de conhecimento em instituições financeiras e sobre a circulação de ideias sobre 
a economia. Não se trata de qualquer regime monetário, mas aquele que emerge a partir das estratégias adotadas por bancos centrais em meio à crise do mercado financeiro de 2008. Esse é um conjunto de ideias altamente experimental que é posto em operação desde a década de 1990 que trouxe para a economia a preocupação de com dados microfundacionais como o comportamento dos agentes econômicos, os ciclos de negócio e as expectativas dos indivíduos influenciam o comportamento da moeda.

Bancos centrais são responsáveis pela implementação de sistemas monetários. Isso significa que sua preocupação é dirigia à estabilidade da moeda a partir da articulação entre preço e confiança, intervindo a partir da oferta de moeda e crédito. Em suma, bancos centrais lidam a todo momento com a quantidade de moeda disponível, juros e preços.

O principal impacto desse corpo teórico dentro da economia foi trazer a questão de como os agentes efetivamente tomam decisões na economia real para dentro do regime monetário. Com isso, os bancos centrais passaram a assumir uma importante função comunicativa e simbólica: produzir a confiança na moeda e na economia como um todo.

Parece bastante claro para Holmes que os central bankers ${ }^{3}$ que se tornaram seus interlocutores consideram que o comportamento dos preços e da inflação na economia é “expectacional”, ou seja, impregnado de expectativas e aspirações dos agentes econômicos nos mais diversos setores da economia. Esses afetos são definidos pelo autor como sutis e voláteis, visões de futuro situacionais e contextuais que podem mudar rapidamente diante de impressões, notícias, eventos, em suma, mudam a partir da experiência desses próprios agentes.

Isso fez com que parte do trabalho dos bancos centrais se tornasse exatamente gerir as expectativas do grande público a partir de modelos de modelagem técnica que Holmes chama de Economia de Palavras $^{4}$. O conceito de Economia das palavras tenta dar conta dos processos através dos quais central bankers produzem alegorias e narrativas sobre a economia que falam sobre fé, confiança e visão positiva de futuro com base em dados econométricos e estatísticos.

O objetivo dessa Economia de Palavras é produzir o maior impacto persuasivo possível nos mais diversos setores da economia para ancorar o valor da moeda e estabili-zar o sistema monetário. A criação do sistema monetário ideal depende do quanto o grande público acredita que esse cenário já existe no presente. Para isso, economistas fazem uso de categorias que afetam profundamente o imaginário das audiências. O paradigma contemporâneo a partir do qual políticas monetárias são pensadas e implementadas presume um tipo de engajamento ativo do público com a economia. Os indivíduos devem ser recrutados para também fazer parte da solução das crises monetárias.

Isso implica um contínuo, constante e extenuante trabalho relacional e representacional sempre por fazer. Holmes se deparou com sujeitos cujas práticas eram muito semelhantes às suas próprias práticas etnográficas no que toca a construção da alteridade. Economistas extraem dados de experiência a partir de uma rede heterogênea de representantes de diversos segmentos, avaliam suas expectativas e sentimentos com relação à economia para, a partir desse conhecimento contextual e situado, modelar representações dinâmicas da economia em pronunciamentos públicos, relatórios, apresentações, discursos e qualquer outra modalidade de trabalho comunicacional. 
Isso leva Holmes a defender a amplificação da hipótese da economia como performance como proposta por Michel Callon e Donald Mackenzie: as narrativas produzidas nos bancos centrais não seria meras interpretações da economia ou referências abstratas a estados de espírito, mas sim pensadas, projetadas, desenhadas para provocar efeitos econômicos a partir da própria experiência dos agentes.

A noção de performatividade de Holmes entende a operação da economia como um campo comunicacional. A contínua geração de ideias e informação sobre a economia possui valor pragmático e compõe parte de um instrumental de intervenção econômica. Palavras são, portanto, pensadas em um duplo registro de performance: os efeitos numéricos, estatísticos e quantitativos da capacidade de economistas e instituições financeiras de dramatizar e representar a experiência de sujeitos imersos em contingências cotidianas.

O conjunto analítico que se forma a partir dessa estratégia de pesquisa é uma bricolagem entre cenas, situações, eventos midiáticos, conversas informais, entrevistas com central bankers e documentos emitidos pelas instituições, não tanto uma descrição contínua e extensiva da vida dentro dos bancos centrais. Holmes não problematiza propriamente sua estratégia de trabalho de campo, mas certamente a leitura suscita reflexões a respeito da presença do antropólogo entre elites tecnocráticas em espaços de poder, especialmente, o que permite que um pesquisador seja incorporado em campo por esses sujeitos e qual o tipo de acesso que é possível ter nesse tipo de empreendimento etnográfico.

A obra é composta por quatorze capítulos. Os quatro primeiros capítulos buscam sedimentar o conceito de Economia das Palavras. Douglas Holmes se dedica a pensar especialmente como economistas traduzem teorias econômicas e monetárias para uma linguagem capaz de afetar o grande público, assim como de que maneira tentam resolver a questão representacional dentro da própria disciplina.

O primeiro, intitulado "Creating a monetary regime” expõe considerações sobre a eficácia de uma política monetária como dependente desse empreendimento representacional e a importância da linguagem na produção de regimes monetários. No segundo, “Communicative imperatives", Holmes evidencia como os bancos centrais buscam produzir uma imagem de futuro com elementos discerníveis aos quais subscrevem representações de fé, confiança e crédito como instrumentos para gerir expectativas. O terceiro capítulo, "Markets are a function of language", trata dos modos através dos quais economistas lidam com a fricção entre teorias econômicas, modelos econométricos e representações numéricas, a experiência de agentes econômicos e a necessidade de produzir um conhecimento monetário. O quarto capítulo, chamado "Apprehensions", fala a respeito das estratégias usadas pelos sujeitos para resolver o dilema output-gap dentro da teoria econômica. Se trata de um paradoxo temporal: economistas agem conforme dados do passado esperando influenciar o futuro.

O quinto, sexto e sétimo capítulos exploram o contexto a partir do qual o novo paradigma monetário e os protocolos de inflation targeting foram produzidos no horizonte disciplinar. O quinto capítulo, "Kultul”, trata da composição dos protocolos contemporâneos de "inflation targeting" como fundamentados em idéias de transparência, comunicação, eficiência e estabilidade. O capítulo "Temporality" trabalha especialmente com a composição do banco central Reserve Bank of New Zealand para pensar o modo como estruturas de sentimento de identidade indígena e impregnadas por uma história colonial são incorporadas a sistemas monetários que operam paradigmas econômicos ocidentais. $\mathrm{O}$ sétimo 
capítulo, "Simulations", trata da noção de eficácia dos modelos econométricos contemporâneos, centrada em sua capacidade de avaliar como vários eventos econômicos são transmitidos ao longo dos canais da economia como um todo, mais do que necessariamente gerar previsões precisas sobre o futuro.

Os capítulos que seguem apresentam descrições etnográficas densas e multi-situadas nas quais Holmes tenta capturar como economistas lidam com fronteiras de seu próprio conhecimento nos contextos limítrofes que caracterizaram a econômica a partir da crise de 2008. Fica evidente a importância que as palavras e as formas de representação da econômica tiveram nas estratégias implementadas pelos bancos centrais que fizeram parte de seu trabalho de campo.

No oitavo capítulo chamado "Inflationary tempest" Holmes discute a partir de dados etnográficos coletados durante a crise inflacionária da Nova Zelância em 2007 e 2008 sua proposta de Economia de Palavras. O nono capítulo, intitulado "Liquidity-tap Economics", evidencia como economistas lidaram com a possibilidade de ocorrência de liquidity-tap durante os períodos mais agudos da crise de 2008, fenômeno previsto pela teoria econômica no qual intervenções monetárias convencionais tem pouco ou nenhum impacto sobre a economia.

No décimo capítulo "The overheard conversation", o autor trabalha com os desdobramentos da política monetária implementada por Svensson, especialmente o monitoramento de conversas de diversos públicos sobre expectativas econômicas. O décimo-primeiro capítulo chamado "Intelligence" trabalha a questão da gestão da informação e de inteligência dentro dos bancos centrais. $\mathrm{O}$ capítulo "Representational Labour" continua a desenvolver a proposta do autor de "trabalho representacional" como parte do instrumental de uma Economia de Palavras, que implica o contínuo processamento de informação e refinamento de categorias que os diversos públicos usam para falar sobre economia.

O décimo-terceiro capítulo, "Manifesto for a public currency" evidencia como as políticas monetárias situaram o problema da crise como não só um problema econômico, mas sobretudo social e por mim, o décimo-quarto e último capítulo intitulado "Totality of promises" retoma a questão do caráter promissório que a política monetária contemporânea adquiriu ao longo das últimas décadas, assim como principais contribuições teóricas e conceituais da obra como um todo.

Economy of Words é uma obra importante para os debates atuais da Antropologia Econômica. Douglas Holmes nos apresenta uma trajetória etnográfica de fôlego capaz de colocar em questão o que está em jogo na definição de políticas monetárias contemporâneas, ao mesmo tempo em que dirige um olhar sensível, cuidadoso e preciso a sujeitos em posição de poder.

\section{Louise Scoz Pasteur de Faria é doutoranda em Antropologia Social pela Univer- sidade Federal do Rio Grande do Sul (UFRGS).}

RECEBIDO: $01 / 08 / 2016$

APROVADO: $05 / 12 / 2016$ 